Article

\title{
Application of an Artificial Fish Swarm Algorithm in an Optimum Tuned Mass Damper Design for a Pedestrian Bridge
}

\author{
Weixing Shi ${ }^{1}$, Liangkun Wang ${ }^{1}$, Zheng $\mathrm{Lu}^{1,2, * \mathbb{B}}$ and Quanwu Zhang ${ }^{3}$ \\ 1 Research Institute of Structural Engineering and Disaster Reduction, Tongji University, Shanghai 200092, \\ China; swxtgk@tongji.edu.cn (W.S.); 1630634@tongji.edu.cn (L.W.) \\ 2 State Key Laboratory of Disaster Reduction in Civil Engineering, Tongji University, Shanghai 200092, China \\ Shanghai Zhili Vibration Technology Co., Ltd., Shanghai 200092, China; 2151xanxus@tongji.edu.cn \\ * Correspondence: luzheng111@tongji.edu.cn; Tel: +86-21-6598-6186
}

Received: 26 December 2017; Accepted: 24 January 2018; Published: 25 January 2018

\begin{abstract}
Tuned mass damper (TMD) has a wide application in the human-induced vibration control of pedestrian bridges and its parameters have great influence on the control effects, hence it should be well designed. A new optimization method for a TMD system is proposed in this paper, based on the artificial fish swarm algorithm (AFSA), and the primary structural damping is taken into consideration. The optimization goal is to minimize the maximum dynamic amplification factor of the primary structure under external harmonic excitations. As a result, the optimized TMD has a smaller maximum dynamic amplification factor and better robustness. The optimum TMD parameters for a damped primary structure with different damping ratios and different TMD mass ratios are summarized in a table for simple, practical design, and the fitting equation is also provided. The TMD configuration optimized by the proposed method was shown to be superior to that optimized by other classical optimization methods. Finally, the application of an optimized TMD based on AFSA for a pedestrian bridge is proposed as a case study. The results show that the TMD designed based on AFSA has a smaller maximum dynamic amplification factor than the TMD designed based on the classic Den Hartog method and the TMD designed based on the Ioi Toshihiro method, and the optimized TMD has a good effect in controlling human-induced vibrations at different frequencies.
\end{abstract}

Keywords: tuned mass damper; human-induced vibrations; pedestrian bridge; artificial fish swarm algorithm; passive control

\section{Introduction}

Pedestrian bridges are more and more common in urban regions. However, with the development of architectural creativeness and structural technologies, they are becoming lighter and more slender, which might lead to serviceability problems under human-induced vibrations [1]. These pedestrian bridges usually have low inherent damping, and large vibrations may be caused by resonance because their natural frequency is usually located within the range of pedestrians' stride frequency. A notable vibration will not only cause serviceability problems but also threaten structural safety.

Tuned mass dampers (TMD) are one of the most traditional vibration control devices [2-6], and it usually consists of a mass, some springs and damping elements [7]. Because TMDs have the advantages of small size and little interference to pedestrian bridges, they are widely used to control human-induced vibrations and solve the serviceability problem [8-10]. The vibration response of a pedestrian bridge is controlled by the inertia force given by the TMD, and the vibration energy of the TMD will be dissipated through its damping element [11-13]. TMD is a single degree of freedom 
vibration absorber, the three dynamic parameters of TMD, which are mass, stiffness and damping coefficient, have a great influence on its control effect.

TMDs have been researched and used to solve the serviceability problem of pedestrian bridges by many researchers. Casciati et al. [14] proposed a contribution to the modelling of pedestrian-induced excitation of footbridges. Brownjohn et al. [15] used human-induced dynamic excitation to estimate modal mass in pedestrian bridges. Nakhorn et al. [16] proposed the application of non-linear multiple TMDs to suppress human-induced vibrations of a footbridge. Chen et al. [17] introduced the performance enhancement of a long-span bridge using tune mass dampers. Carpineto et al. [18] proposed the application of multiple TMDs to control human-induced vibrations in suspension footbridges. Lu et al. [19] studied the application of TMD to control pedestrian-induced vibration of the Expo Culture Centre. Li et al. [20] studied the pedestrian-induced random vibration of pedestrian bridges and vibration control methods using multiple TMDs. Lievens et al. [21] introduced the robust design and application of a TMD in a footbridge. Caetano et al. [22] studied controlling pedestrian-induced vibrations of a footbridge using tuned mass dampers. Casciati et al. [23] introduced the vibration control effect of multiple TMDs in the towers of bridges.

The mass ratio and damping ratio of a TMD will affect its vibration control effect, and TMD is especially sensitive to the frequency ratio [24-28]. Therefore, the three dynamic parameters of TMD should be well designed. The classic Den Hartog method [29] has a wide application in TMD design. Besides, many new design methods are proposed. In order to search the optimum parameters of TMD for different optimization goals, a natured-inspired computational algorithm has been used for parameters optimization of TMDs by many researchers. Leung et al. [30,31] proposed the particle swarm optimization of TMDs by non-stationary base excitation during earthquake. Bekdas et al. [32] introduced the estimating optimum parameters of tuned mass dampers using harmony search. Mohebbi et al. [33] designed optimal multiple tuned mass dampers using genetic algorithms (GAs) to mitigate the seismic response of structures. Jiménez-Alonso et al. [34] introduced the robust optimum design of TMDs to mitigate pedestrian-induced vibrations using multi-objective genetic algorithms. Therefore, the natured-inspired algorithms play an important role in TMD parameter optimization. Considering the advantages of flexibility, great convergence speed, great accuracy, fault tolerance, etc. $[35,36]$, the artificial fish swarm algorithm (AFSA) is applied to optimize TMD parameters in controlling the human-induced vibrations of footbridges.

The maximum acceleration of a pedestrian bridge under human-induced vibrations is one of the most important indexes to evaluate the serviceability problem [1]. The classic Den Hartog method [29] has a wide application in TMD design; however, it does not consider the damping of the primary system, which may lead to a defective TMD. Currently, practical application analytical proposals that overcome some of the limitations of the Den Hartog proposal, are applied. Ioi and Ikeda $[37,38]$ proposed an improved design method considering structural damping, whose optimization goal is to minimize the maximum acceleration dynamic amplification factor of the primary structure under external harmonic excitations. Butz et al. [39] proposed advanced load models for synchronous pedestrian excitation and optimized design guidelines for steel footbridges. Van et al. [40] introduced the numerical and experimental evaluation of the dynamic performance of a footbridge with tuned mass dampers. Asami et al. [41] studied the analytical solutions to $\mathrm{H}_{\infty}$ and $\mathrm{H}_{2}$ optimization of dynamic vibration absorbers attached to damped linear systems. In order to depress the maximum acceleration dynamic amplification factor of the primary structure under external excitation and strengthen the robustness of TMD, a novel optimization method based on the artificial fish swarm algorithm (AFSA) is proposed in this paper, considering the structural damping ratio. The optimization goal is the same as the aforementioned.

In this paper, the new design method is first introduced and then it is verified through a case study. The contents are arranged as follows: Section 2 presents the AFSA and introduces the new design method of the TMD. Section 3 presents the optimum TMD parameters table and optimization design equations for the TMD damping ratio and frequency ratio. In Section 4, the accuracy of the 
proposed design method and the vibration control effect of the optimized TMD is verified through a case study.

\section{Optimization Algorithm of TMD}

\subsection{Artificial Fish Swarm Algorithm}

Swarm intelligence algorithms have a wide application in many areas to solve different problems. Swarm intelligence algorithms consist of many algorithms that are developed by imitating the behavior of animals in nature [35,36]. The artificial fish swarm algorithm (AFSA) is one of the swarm intelligence algorithms. The actions of individual fish and the information interactions among them, when they are foraging and preying, are focused by the AFSA [42]. The AFSA is inspired by the individual, group and social behaviors of the fish. In a social form, it is searching for food, immigration, dealing with dangers and interactions between the fish in a swarm that result in intelligent group behavior $[43,44]$. The AFSA has many advantages such as flexibility, great convergence speed, great accuracy, fault tolerance and so on [45].

Fish do not have the complex logical reasoning ability and comprehensive judgment ability of human beings. Their purpose is achieved through the simple behavior of individuals or groups. It can be found through observing fish activities that they have four basic behaviors which are preying, swarming, following and random behavior. The four behaviors can be interchanged under different conditions. By evaluating their behavior, fish can choose an optimal behavior to achieve higher food concentration.

Among the four behaviors of artificial fish, the preying behavior is a fundamental behavior, which focuses mainly on searching of food. It is usually taken into consideration that artificial fish generally find the tendency to perceive the amount or concentration of food in the water by sight or taste. $X_{i}$ is the artificial fish current state and in its visual distance, it will select a new state $X_{j}$ randomly. $Y$ is the food concentration, which means the value of the objective function. The artificial fish will find the global extreme value when the Visual is greater, and it will converge more easily. Rand() is a random number between 0 and 1 .

$$
X_{j}=X_{i}+\operatorname{Visual} \cdot \operatorname{Rand}()
$$

In the maximum problem, if $Y_{i}<Y_{j}$, the artificial fish will go forward a Step, which is a preset number in this direction.

$$
X_{i}^{t+1}=X_{i}^{t}+\frac{X_{j}-X_{i}^{t}}{\left\|X_{j}-X_{i}^{t}\right\|} \cdot \text { Step } \cdot \operatorname{Rand}()
$$

If not, the artificial fish will choose a new state $X_{j}$ randomly and judge whether it fits for the progressive condition. If the $X_{j}$ still cannot fit it, the artificial fish will move a Step randomly.

In the process of swarming, fish usually congregate in groups, which is a kind of life habit formed to guarantee the survival of the colony and keep away from danger. Each artificial fish is made as follows: it tries to swarm to the center of the neighboring partner and avoid overcrowding. $n_{f}$ is the number of the center position artificial fish's companions in its Visual distance $\left(\left\|X_{j}-X_{i}^{t}\right\| \leq\right.$ Visual $)$ and $X_{c e n t e r}$ is the center position.

$$
X_{\text {center }}=\frac{\sum_{j=1}^{n_{f}} X_{j}}{n_{f}}
$$

If $Y_{\text {center }}>Y_{i}$ and $\frac{n_{f}}{n}<\delta$ ( $n$ is the number of total fish and $\delta$ is the crowding factor which is preset), this means that the center position has more food, which means that the value of fitness function is higher, and it is not very crowded, so the artificial fish will move a Step to the center.

$$
X_{i}^{t+1}=X_{i}^{t}+\frac{X_{\text {center }}-X_{i}^{t}}{\left\|X_{\text {center }}-X_{i}^{t}\right\|} \cdot \text { Step } \cdot \operatorname{Rand}()
$$


If not, it will execute the preying behavior. In the swarming factor, the function of the crowd factor is to limit the scale of swarms. Therefore, more artificial fish only cluster at the best area, and a situation in which the artificial fish moves to optimum in a wide field is ensured.

When a fish finds more food and less crowded areas, nearby artificial fish will follow and quickly swim to the food. In the artificial fish's perception range, if it finds a partner in the optimal position, then it will move one Step towards it, otherwise, the preying operator is performed. The following operator speeds up the movement of the artificial fish to a better location, which also encourages the artificial fish to move to a better position.

The fish swims freely in the water, which seems to be random. However, actually, they are looking for food or companions in a larger range. The description of random behavior is simple, which is to randomly select a state in the field of view, and then move in that direction. The random behavior is also an unredeemed behavior of preying behavior.

The evaluation of artificial fish behavior is a way to reflect the autonomous behavior of fish. In solving the problem of optimization, the following two kinds of evaluation method can be chosen: one is to choose the optimal execution behavior. Given the current state of the way, the largest behavior in the optimal direction will be chosen. The other is to choose a behavior that can ensure that the artificial fish will go in a better direction.

\subsection{Optimization Goal}

The following dynamic system is consisted of a single degree of freedom primary structure and a TMD, excited by an external excitation $F(t)$, shown in Figure 1.

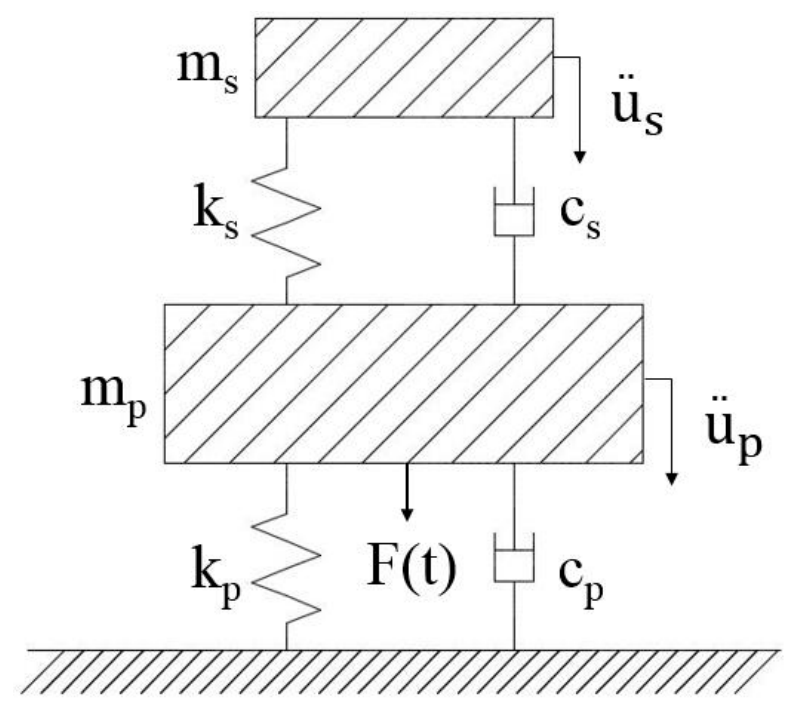

Figure 1. The dynamic system coupled with a tuned mass dampers (TMD) under an external excitation.

When the external excitation is assumed to take the form $F(t)=F_{0} \mathrm{e}^{\mathrm{i} \omega t}$, where $F_{0}$ is the forcing amplitude and $\omega$ is its frequency. The motion equations of the dynamic system under an external excitation can be written as [1]:

$$
\left(\begin{array}{cc}
m_{p} & 0 \\
0 & m_{s}
\end{array}\right)\left(\begin{array}{l}
\ddot{u}_{p} \\
\ddot{u}_{s}
\end{array}\right)+\left(\begin{array}{cc}
c_{p}+c_{s} & -c_{s} \\
-c_{s} & c_{s}
\end{array}\right)\left(\begin{array}{l}
\dot{u}_{p} \\
\dot{u}_{s}
\end{array}\right)+\left(\begin{array}{cc}
k_{p}+k_{s} & -k_{s} \\
-k_{s} & k_{s}
\end{array}\right)\left(\begin{array}{c}
u_{p} \\
u_{s}
\end{array}\right)=\left(\begin{array}{c}
F_{0} \mathrm{e}^{\mathrm{i} \omega \mathrm{t}} \\
0
\end{array}\right)
$$

where $m_{p}$ and $m_{s}$ are the mass of the primary structure and the TMD, respectively. $c_{p}$ and $c_{s}$ are the viscous damping coefficient of the primary structure and the TMD, respectively. $k_{p}$ and $k_{s}$ denote the stiffness coefficient of the primary structure and the TMD, respectively. $u_{p}$ and $u_{s}$ denote the absolute displacement of the primary structure and the TMD, respectively. The raised dot indicates the derivative with respect to time. 
Besides, the excitation frequency ratio $\beta=\frac{\omega}{\omega_{p}}$, the TMD frequency ratio $\gamma=\frac{\omega_{s}}{\omega_{p}}$ and the TMD mass ratio $\mu=\frac{m_{s}}{m_{p}}$ are utilized.

Under human-induced vibrations, the maximum acceleration of the pedestrian bridge is one of the most important indexes to evaluate the serviceability problem. In order to depress the maximum acceleration dynamic amplification factor of the pedestrian bridge under external excitation and strengthen the robustness of the TMD, in this section, the novel optimization method of TMD is based on the AFSA, considering the structural damping ratio. The optimization goal is to minimize the maximum acceleration dynamic amplification factor of the pedestrian bridge under external harmonic excitations, based on the AFSA.

The acceleration dynamic amplification factor of the pedestrian bridge under a harmonic excitation can be written as:

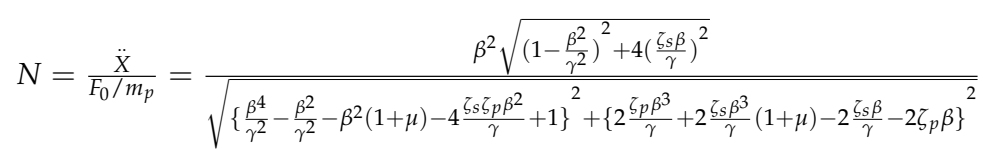

where $\zeta_{p}$ and $\zeta_{s}$ are the damping ratio of primary structure and TMD, respectively.

\section{Optimum TMD Parameters Based on AFSA}

\subsection{Optimum TMD Parameters and Fitting Formulas}

In this section, the optimum TMD frequency ratio $f_{o p t}$, TMD damping ratio $\zeta_{o p t}$ and dynamic amplification factor $N_{\text {opt }}$ are shown in Table 1.

To illustrate this more clearly, the comparison of the optimum parameters of TMD systems for different mass ratios and damping ratios of the primary structure under external harmonic excitations are presented in Figure 2.

It can be seen from Figure 2a that with the increasing of the TMD mass ratio, the optimum TMD frequency ratio decreases, and with the increasing of the structural damping ratio, the optimum TMD frequency ratio increases too. It is shown in Figure $2 b$ that with the increasing of the mass ratio, the optimum TMD damping ratio also increases, and with the increasing of the structural damping ratio, the optimum TMD damping ratio has a small incensement. It is presented in Figure $2 c$ that with the increasing of mass ratio, the optimum dynamic amplification factor decreases, and with the increasing of structural damping ratio, the optimum dynamic amplification factor decreases steeply for a small mass ratio and smoothly for a large mass ratio.

The explicit expressions for the optimum TMD frequency ratio and optimum TMD damping ratio are given as follows, which result from data fitting through the least square method.

$$
\begin{gathered}
f_{\text {opt }}=0.999-0.421 \mu+0.0456 \zeta_{p}-0.588 \mu^{2}+1.2477 \mu \zeta_{p}+1.1325 \zeta_{p}^{2} \\
\zeta_{\text {opt }}=0.607 \sqrt{\mu}+0.120 \mu+0.129 \zeta_{p}-3.423 \mu^{2}-0.485 \zeta_{p}^{2}+2.312 \mu \zeta_{p} \\
\quad+22.347 \mu^{3}+3.088 \zeta_{p}^{3}-8.366 \mu^{2} \zeta_{p}+0.421 \mu \zeta_{p}^{2}
\end{gathered}
$$

To verify the accuracy of the fitting Formulas (9) and (10), the fitting error between the formulas and Table 1 are shown in Figure 3.

It is presented in Figure $3 a$ that the fitting error of optimum frequency ratio are all smaller than $0.3 \%$. It is presented in Figure $3 \mathrm{~b}$ that the fitting error of optimum damping ratio are all smaller than $1.0 \%$. Therefore, the fitting formulas agree well with Table 1. Optimum TMD parameters can be obtained from Table 1 or calculated from Formulas (7) and (8). 
Table 1. Optimum TMD parameters for a damped primary structure under external force excitation based on AFSA for a specified mass ratio. TMD: tuned mass dampers; AFSA: artificial fish swarm algorithm.

\begin{tabular}{|c|c|c|c|c|c|c|c|c|c|c|c|c|c|c|c|}
\hline \multirow{2}{*}{$\mu$} & \multicolumn{3}{|c|}{$\zeta_{p}=0.01$} & \multicolumn{3}{|c|}{$\zeta_{p}=0.02$} & \multicolumn{3}{|c|}{$\zeta_{p}=0.03$} & \multicolumn{3}{|c|}{$\zeta_{p}=0.04$} & \multicolumn{3}{|c|}{$\zeta_{p}=0.05$} \\
\hline & $f_{o p t}$ & $\zeta_{\text {opt }}$ & $N_{o p t}$ & $f_{o p t}$ & $\zeta_{o p t}$ & $N_{o p t}$ & $f_{o p t}$ & $\zeta_{\text {opt }}$ & $N_{o p t}$ & $f_{o p t}$ & $\zeta_{\text {opt }}$ & $N_{o p t}$ & $f_{o p t}$ & $\zeta_{\text {opt }}$ & $N_{o p t}$ \\
\hline 0.001 & 1.000 & 0.019 & 24.024 & 1.001 & 0.024 & 17.000 & 1.002 & 0.025 & 12.877 & 1.003 & 0.026 & 10.341 & 1.004 & 0.027 & 8.616 \\
\hline 0.002 & 1.000 & 0.032 & 20.227 & 1.000 & 0.028 & 14.782 & 1.001 & 0.032 & 11.562 & 1.001 & 0.035 & 9.502 & 1.003 & 0.032 & 8.054 \\
\hline 0.003 & 0.999 & 0.030 & 17.676 & 1.000 & 0.034 & 13.354 & 1.001 & 0.038 & 10.725 & 1.002 & 0.037 & 8.931 & 1.003 & 0.038 & 7.636 \\
\hline 0.004 & 0.999 & 0.038 & 15.907 & 0.999 & 0.044 & 12.399 & 1.000 & 0.043 & 10.102 & 1.001 & 0.042 & 8.499 & 1.003 & 0.046 & 7.332 \\
\hline 0.005 & 0.998 & 0.048 & 14.698 & 0.999 & 0.046 & 11.665 & 1.000 & 0.047 & 9.592 & 1.001 & 0.051 & 8.151 & 1.003 & 0.050 & 7.078 \\
\hline 0.006 & 0.998 & 0.049 & 13.804 & 0.998 & 0.048 & 11.019 & 0.999 & 0.053 & 9.182 & 1.001 & 0.050 & 7.851 & 1.003 & 0.051 & 6.842 \\
\hline 0.007 & 0.998 & 0.049 & 12.937 & 0.998 & 0.055 & 10.504 & 0.999 & 0.055 & 8.826 & 1.001 & 0.058 & 7.592 & 1.002 & 0.059 & 6.651 \\
\hline 0.008 & 0.997 & 0.056 & 12.258 & 0.998 & 0.059 & 10.076 & 0.999 & 0.061 & 8.531 & 1.000 & 0.060 & 7.373 & 1.002 & 0.061 & 6.496 \\
\hline 0.009 & 0.996 & 0.061 & 11.724 & 0.997 & 0.065 & 9.720 & 0.998 & 0.060 & 8.266 & 0.999 & 0.065 & 7.176 & 1.001 & 0.067 & 6.342 \\
\hline 0.010 & 0.996 & 0.065 & 11.269 & 0.997 & 0.063 & 9.400 & 0.998 & 0.065 & 8.022 & 0.999 & 0.067 & 7.002 & 1.001 & 0.065 & 6.197 \\
\hline 0.015 & 0.993 & 0.077 & 9.533 & 0.994 & 0.081 & 8.161 & 0.996 & 0.077 & 7.121 & 0.997 & 0.083 & 6.304 & 0.999 & 0.083 & 5.656 \\
\hline 0.020 & 0.992 & 0.086 & 8.439 & 0.992 & 0.090 & 7.336 & 0.994 & 0.093 & 6.490 & 0.995 & 0.095 & 5.811 & 0.997 & 0.097 & 5.254 \\
\hline 0.025 & 0.988 & 0.099 & 7.672 & 0.990 & 0.098 & 6.756 & 0.991 & 0.101 & 6.026 & 0.994 & 0.102 & 5.438 & 0.995 & 0.104 & 4.947 \\
\hline 0.030 & 0.986 & 0.109 & 7.072 & 0.988 & 0.109 & 6.285 & 0.989 & 0.114 & 5.655 & 0.991 & 0.112 & 5.134 & 0.992 & 0.118 & 4.699 \\
\hline 0.035 & 0.984 & 0.116 & 6.602 & 0.986 & 0.113 & 5.913 & 0.987 & 0.119 & 5.348 & 0.989 & 0.120 & 4.881 & 0.992 & 0.121 & 4.485 \\
\hline 0.040 & 0.982 & 0.125 & 6.209 & 0.983 & 0.127 & 5.597 & 0.984 & 0.130 & 5.091 & 0.987 & 0.130 & 4.668 & 0.988 & 0.134 & 4.306 \\
\hline 0.045 & 0.980 & 0.130 & 5.885 & 0.980 & 0.135 & 5.333 & 0.983 & 0.133 & 4.870 & 0.984 & 0.138 & 4.481 & 0.987 & 0.137 & 4.146 \\
\hline 0.050 & 0.977 & 0.138 & 5.599 & 0.979 & 0.141 & 5.098 & 0.980 & 0.143 & 4.674 & 0.982 & 0.146 & 4.316 & 0.984 & 0.148 & 4.006 \\
\hline 0.055 & 0.974 & 0.149 & 5.360 & 0.976 & 0.146 & 4.897 & 0.977 & 0.152 & 4.507 & 0.980 & 0.150 & 4.171 & 0.982 & 0.153 & 3.882 \\
\hline 0.060 & 0.973 & 0.149 & 5.141 & 0.975 & 0.151 & 4.715 & 0.976 & 0.155 & 4.350 & 0.978 & 0.157 & 4.038 & 0.981 & 0.158 & 3.766 \\
\hline 0.065 & 0.970 & 0.157 & 4.950 & 0.971 & 0.163 & 4.554 & 0.974 & 0.162 & 4.215 & 0.975 & 0.168 & 3.922 & 0.978 & 0.167 & 3.665 \\
\hline 0.070 & 0.967 & 0.165 & 4.781 & 0.970 & 0.164 & 4.409 & 0.972 & 0.165 & 4.090 & 0.974 & 0.169 & 3.812 & 0.977 & 0.169 & 3.570 \\
\hline 0.075 & 0.966 & 0.167 & 4.621 & 0.968 & 0.170 & 4.273 & 0.969 & 0.173 & 3.973 & 0.972 & 0.173 & 3.713 & 0.974 & 0.178 & 3.481 \\
\hline 0.080 & 0.964 & 0.173 & 4.481 & 0.965 & 0.176 & 4.154 & 0.967 & 0.180 & 3.869 & 0.969 & 0.180 & 3.621 & 0.972 & 0.183 & 3.401 \\
\hline 0.085 & 0.961 & 0.180 & 4.351 & 0.964 & 0.180 & 4.042 & 0.965 & 0.184 & 3.772 & 0.968 & 0.184 & 3.535 & 0.970 & 0.187 & 3.327 \\
\hline 0.090 & 0.959 & 0.184 & 4.230 & 0.961 & 0.186 & 3.936 & 0.963 & 0.190 & 3.680 & 0.965 & 0.191 & 3.454 & 0.968 & 0.194 & 3.255 \\
\hline 0.095 & 0.956 & 0.192 & 4.119 & 0.958 & 0.192 & 3.841 & 0.959 & 0.198 & 3.597 & 0.962 & 0.200 & 3.381 & 0.965 & 0.200 & 3.190 \\
\hline 0.100 & 0.955 & 0.192 & 4.018 & 0.956 & 0.199 & 3.752 & 0.958 & 0.199 & 3.519 & 0.961 & 0.199 & 3.312 & 0.963 & 0.205 & 3.128 \\
\hline
\end{tabular}


Table 1. Cont.

\begin{tabular}{|c|c|c|c|c|c|c|c|c|c|c|c|c|c|c|c|}
\hline \multirow{2}{*}{$\mu$} & \multicolumn{3}{|c|}{$\zeta_{p}=0.06$} & \multicolumn{3}{|c|}{$\zeta_{p}=0.07$} & \multicolumn{3}{|c|}{$\zeta_{p}=0.08$} & \multicolumn{3}{|c|}{$\zeta_{p}=0.09$} & \multicolumn{3}{|c|}{$\zeta_{p}=0.10$} \\
\hline & $f_{o p t}$ & $\zeta_{\text {opt }}$ & $N_{o p t}$ & $f_{o p t}$ & $\zeta_{o p t}$ & $N_{o p t}$ & $f_{o p t}$ & $\zeta_{o p t}$ & $N_{o p t}$ & $f_{o p t}$ & $\zeta_{o p t}$ & $N_{o p t}$ & $f_{o p t}$ & $\zeta_{\text {opt }}$ & $N_{o p t}$ \\
\hline 0.001 & 1.005 & 0.023 & 7.388 & 1.007 & 0.029 & 6.468 & 1.009 & 0.023 & 5.747 & 1.011 & 0.024 & 5.170 & 1.012 & 0.032 & 4.703 \\
\hline 0.002 & 1.005 & 0.031 & 6.976 & 1.006 & 0.037 & 6.152 & 1.008 & 0.037 & 5.505 & 1.011 & 0.039 & 4.979 & 1.013 & 0.039 & 4.542 \\
\hline 0.003 & 1.005 & 0.040 & 6.670 & 1.007 & 0.040 & 5.922 & 1.009 & 0.040 & 5.318 & 1.011 & 0.044 & 4.831 & 1.013 & 0.045 & 4.425 \\
\hline 0.004 & 1.004 & 0.049 & 6.443 & 1.006 & 0.046 & 5.740 & 1.008 & 0.050 & 5.175 & 1.011 & 0.052 & 4.713 & 1.013 & 0.051 & 4.323 \\
\hline 0.005 & 1.004 & 0.050 & 6.241 & 1.006 & 0.055 & 5.587 & 1.008 & 0.054 & 5.055 & 1.010 & 0.053 & 4.612 & 1.013 & 0.058 & 4.242 \\
\hline 0.006 & 1.004 & 0.055 & 6.070 & 1.007 & 0.054 & 5.451 & 1.008 & 0.056 & 4.941 & 1.010 & 0.060 & 4.523 & 1.013 & 0.059 & 4.168 \\
\hline 0.007 & 1.004 & 0.061 & 5.922 & 1.006 & 0.061 & 5.330 & 1.008 & 0.062 & 4.844 & 1.011 & 0.062 & 4.441 & 1.013 & 0.063 & 4.098 \\
\hline 0.008 & 1.003 & 0.065 & 5.793 & 1.005 & 0.065 & 5.224 & 1.008 & 0.066 & 4.761 & 1.010 & 0.067 & 4.370 & 1.013 & 0.066 & 4.040 \\
\hline 0.009 & 1.003 & 0.065 & 5.671 & 1.005 & 0.071 & 5.130 & 1.007 & 0.070 & 4.682 & 1.010 & 0.071 & 4.303 & 1.012 & 0.075 & 3.983 \\
\hline 0.010 & 1.003 & 0.070 & 5.560 & 1.005 & 0.070 & 5.041 & 1.007 & 0.071 & 4.606 & 1.010 & 0.075 & 4.243 & 1.013 & 0.073 & 3.932 \\
\hline 0.015 & 1.001 & 0.083 & 5.121 & 1.003 & 0.088 & 4.681 & 1.006 & 0.085 & 4.307 & 1.008 & 0.091 & 3.989 & 1.011 & 0.090 & 3.715 \\
\hline 0.020 & 0.999 & 0.099 & 4.797 & 1.001 & 0.099 & 4.407 & 1.004 & 0.102 & 4.078 & 1.007 & 0.102 & 3.792 & 1.010 & 0.102 & 3.546 \\
\hline 0.025 & 0.998 & 0.105 & 4.542 & 1.000 & 0.106 & 4.192 & 1.002 & 0.110 & 3.895 & 1.006 & 0.109 & 3.636 & 1.009 & 0.113 & 3.410 \\
\hline 0.030 & 0.995 & 0.116 & 4.331 & 0.997 & 0.120 & 4.014 & 1.001 & 0.120 & 3.741 & 1.003 & 0.124 & 3.502 & 1.006 & 0.126 & 3.291 \\
\hline 0.035 & 0.994 & 0.123 & 4.151 & 0.996 & 0.125 & 3.860 & 0.999 & 0.129 & 3.608 & 1.002 & 0.131 & 3.386 & 1.005 & 0.133 & 3.190 \\
\hline 0.040 & 0.991 & 0.133 & 3.997 & 0.993 & 0.139 & 3.727 & 0.997 & 0.137 & 3.491 & 0.999 & 0.142 & 3.284 & 1.003 & 0.141 & 3.099 \\
\hline 0.045 & 0.989 & 0.141 & 3.860 & 0.992 & 0.141 & 3.608 & 0.995 & 0.145 & 3.388 & 0.998 & 0.146 & 3.193 & 1.001 & 0.150 & 3.019 \\
\hline 0.050 & 0.987 & 0.151 & 3.738 & 0.989 & 0.152 & 3.501 & 0.993 & 0.153 & 3.294 & 0.996 & 0.154 & 3.110 & 1.000 & 0.155 & 2.945 \\
\hline 0.055 & 0.985 & 0.155 & 3.629 & 0.988 & 0.155 & 3.408 & 0.990 & 0.161 & 3.211 & 0.994 & 0.160 & 3.035 & 0.997 & 0.166 & 2.878 \\
\hline 0.060 & 0.983 & 0.161 & 3.529 & 0.986 & 0.163 & 3.319 & 0.989 & 0.164 & 3.133 & 0.993 & 0.166 & 2.966 & 0.996 & 0.170 & 2.816 \\
\hline 0.065 & 0.980 & 0.170 & 3.440 & 0.983 & 0.172 & 3.240 & 0.986 & 0.173 & 3.062 & 0.989 & 0.177 & 2.903 & 0.994 & 0.177 & 2.759 \\
\hline 0.070 & 0.979 & 0.174 & 3.356 & 0.983 & 0.173 & 3.166 & 0.985 & 0.179 & 2.996 & 0.988 & 0.180 & 2.844 & 0.991 & 0.185 & 2.706 \\
\hline 0.075 & 0.977 & 0.181 & 3.278 & 0.980 & 0.181 & 3.096 & 0.983 & 0.183 & 2.934 & 0.986 & 0.185 & 2.789 & 0.990 & 0.189 & 2.656 \\
\hline 0.080 & 0.974 & 0.188 & 3.207 & 0.977 & 0.190 & 3.033 & 0.981 & 0.190 & 2.877 & 0.983 & 0.194 & 2.737 & 0.988 & 0.195 & 2.609 \\
\hline 0.085 & 0.973 & 0.190 & 3.140 & 0.975 & 0.195 & 2.974 & 0.978 & 0.197 & 2.824 & 0.982 & 0.197 & 2.689 & 0.986 & 0.200 & 2.566 \\
\hline 0.090 & 0.971 & 0.195 & 3.077 & 0.974 & 0.198 & 2.917 & 0.978 & 0.198 & 2.773 & 0.979 & 0.205 & 2.643 & 0.983 & 0.206 & 2.525 \\
\hline 0.095 & 0.967 & 0.205 & 3.018 & 0.970 & 0.207 & 2.864 & 0.974 & 0.208 & 2.725 & 0.978 & 0.209 & 2.599 & 0.981 & 0.213 & 2.485 \\
\hline 0.100 & 0.955 & 0.192 & 4.018 & 0.956 & 0.199 & 3.752 & 0.958 & 0.199 & 3.519 & 0.961 & 0.199 & 3.312 & 0.963 & 0.205 & 3.128 \\
\hline
\end{tabular}




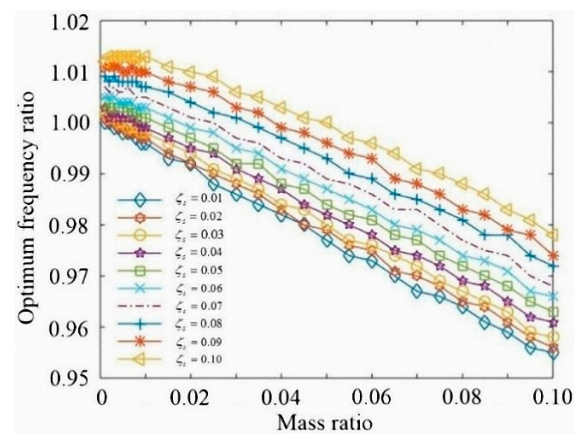

(a)

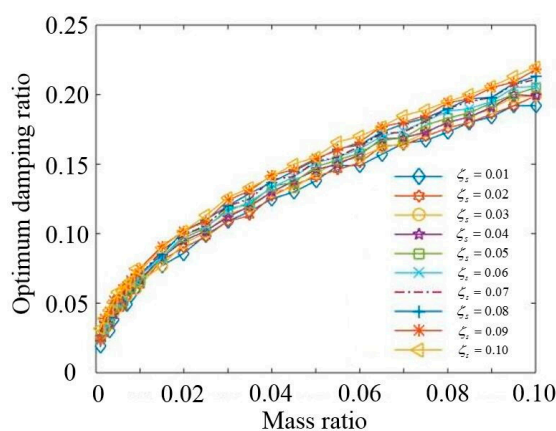

(b)

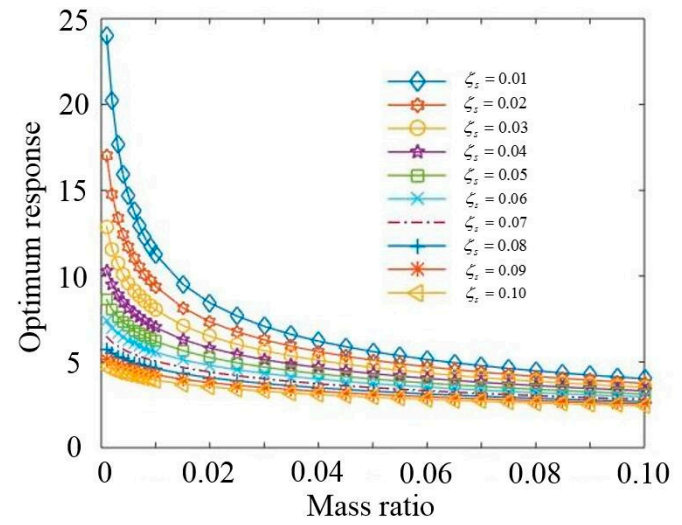

(c)

Figure 2. Comparison of the optimum parameters of TMD systems based on artificial fish swarm algorithm (AFSA) for different mass ratios and damping ratios of the primary structure under external excitations. (a) Comparison of optimum frequency ratio; (b) Comparison of optimum damping ratio; (c) Comparison of optimum response.

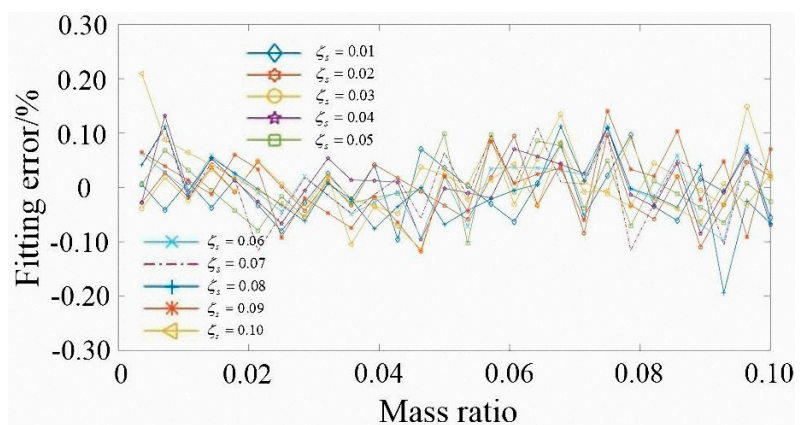

(a)

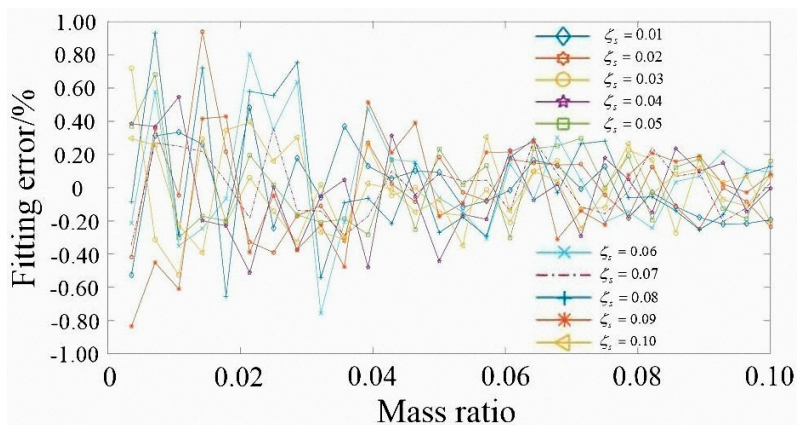

(b)

Figure 3. Comparison of fitting error of fitting formulas. (a) Comparison of optimum frequency ratio; (b) Comparison of optimum damping ratio. 


\subsection{Comparison Study}

The classic Den Hartog method [29] has a wide application in TMD design; however, it does not consider the damping of the primary system, which may lead to a defective TMD. The optimum formulas of the Den Hartog method are shown in following, which is also devoted to minimizing the maximum of the structural acceleration response under external harmonic excitations.

$$
\begin{gathered}
f_{\text {opt }}=\frac{1}{\sqrt{1+\mu}} \\
\zeta_{\text {opt }}=\sqrt{\frac{3 \mu}{8(1+\mu / 2)}}
\end{gathered}
$$

Ioi and Ikeda [37,38] proposed an improved design method considering structural damping, whose optimization goal is to minimize the maximum acceleration dynamic amplification factor of primary structure under external harmonic excitations. The optimum formulas of the Ioi and Ikeda method are shown in the following.

$$
\begin{gathered}
f_{o p t}=\sqrt{\frac{1}{1+\mu}}+\left(0.096+0.88 \mu-1.8 \mu^{2}\right) \zeta_{p}+\left(1.34-2.9 \mu+3 \mu^{2}\right) \zeta_{p}^{2} \\
\zeta_{o p t}=\sqrt{\frac{3 \mu\left(1+0.49 \mu-0.2 \mu^{2}\right)}{8(1+\mu)}}+\left(0.13+0.72 \mu+0.2 \mu^{2}\right) \zeta_{p}+\left(0.19+1.6 \mu-4 \mu^{2}\right) \zeta_{p}^{2}
\end{gathered}
$$

The comparison study between the optimization method based on AFSA proposed in this paper and the classic Den Hartog method is shown in Table 2. The comparison study between

\begin{tabular}{|c|c|c|c|c|c|c|c|c|c|c|}
\hline$\mu$ & 0.010 & 0.020 & 0.030 & 0.040 & 0.050 & 0.060 & 0.070 & 0.080 & 0.090 & 0.100 \\
\hline 0.001 & 1.039 & 1.006 & 1.887 & 1.952 & 1.989 & 2.001 & 2.341 & 2.548 & 2.625 & 2.546 \\
\hline 0.002 & 1.046 & 1.125 & 1.328 & 2.299 & 2.625 & 2.799 & 2.796 & 2.940 & 3.150 & 3.300 \\
\hline 0.003 & 0.503 & 1.402 & 2.281 & 2.553 & 2.622 & 3.117 & 3.366 & 3.532 & 3.486 & 3.537 \\
\hline 0.004 & 0.767 & 1.843 & 2.079 & 2.362 & 3.016 & 3.280 & 3.418 & 3.597 & 3.836 & 4.020 \\
\hline 0.005 & 1.373 & 1.506 & 2.004 & 2.785 & 3.073 & 3.262 & 3.595 & 3.841 & 4.022 & 4.047 \\
\hline 0.006 & 0.869 & 1.357 & 2.417 & 2.891 & 3.133 & 3.542 & 3.843 & 4.026 & 4.074 & 4.325 \\
\hline 0.007 & 1.149 & 1.896 & 2.558 & 2.783 & 3.360 & 3.701 & 3.903 & 4.097 & 4.370 & 4.549 \\
\hline 0.008 & 0.943 & 2.063 & 2.343 & 2.814 & 3.290 & 3.628 & 3.886 & 4.241 & 4.473 & 4.548 \\
\hline 0.009 & 1.232 & 1.862 & 2.078 & 2.979 & 3.326 & 3.577 & 4.048 & 4.311 & 4.501 & 4.719 \\
\hline 0.010 & 1.182 & 1.601 & 2.387 & 2.972 & 3.354 & 3.789 & 4.131 & 4.380 & 4.580 & 4.851 \\
\hline 0.015 & 1.025 & 1.904 & 2.246 & 3.111 & 3.501 & 3.954 & 4.376 & 4.671 & 4.970 & 5.256 \\
\hline 0.020 & 1.121 & 1.977 & 2.607 & 3.074 & 3.758 & 4.088 & 4.587 & 4.938 & 5.220 & 5.554 \\
\hline 0.025 & 0.954 & 1.740 & 2.526 & 3.161 & 3.737 & 4.232 & 4.644 & 5.059 & 5.392 & 5.668 \\
\hline 0.030 & 0.995 & 1.875 & 2.528 & 3.183 & 3.773 & 4.241 & 4.767 & 5.111 & 5.554 & 5.882 \\
\hline 0.035 & 0.937 & 1.795 & 2.580 & 3.235 & 3.844 & 4.371 & 4.821 & 5.273 & 5.610 & 5.996 \\
\hline 0.040 & 1.030 & 1.802 & 2.602 & 3.207 & 3.865 & 4.361 & 4.909 & 5.307 & 5.766 & 6.110 \\
\hline 0.045 & 0.846 & 1.803 & 2.543 & 3.267 & 3.878 & 4.456 & 4.933 & 5.412 & 5.797 & 6.209 \\
\hline 0.050 & 1.057 & 1.811 & 2.661 & 3.239 & 3.954 & 4.441 & 5.044 & 5.453 & 5.933 & 6.291 \\
\hline 0.055 & 0.959 & 1.818 & 2.544 & 3.305 & 3.883 & 4.520 & 4.999 & 5.528 & 5.937 & 6.381 \\
\hline 0.060 & 0.950 & 1.865 & 2.632 & 3.341 & 3.989 & 4.556 & 5.110 & 5.578 & 6.027 & 6.430 \\
\hline 0.065 & 1.010 & 1.790 & 2.621 & 3.263 & 3.975 & 4.532 & 5.117 & 5.609 & 6.079 & 6.512 \\
\hline 0.070 & 0.945 & 1.810 & 2.572 & 3.336 & 3.940 & 4.595 & 5.107 & 5.646 & 6.105 & 6.547 \\
\hline 0.075 & 0.974 & 1.887 & 2.622 & 3.322 & 4.021 & 4.619 & 5.204 & 5.681 & 6.169 & 6.588 \\
\hline 0.080 & 0.954 & 1.799 & 2.620 & 3.290 & 4.018 & 4.604 & 5.199 & 5.722 & 6.203 & 6.670 \\
\hline 0.085 & 0.967 & 1.782 & 2.614 & 3.350 & 3.990 & 4.644 & 5.176 & 5.738 & 6.224 & 6.681 \\
\hline 0.090 & 0.989 & 1.878 & 2.617 & 3.403 & 4.040 & 4.670 & 5.261 & 5.759 & 6.268 & 6.719 \\
\hline 0.095 & 0.956 & 1.850 & 2.620 & 3.359 & 4.043 & 4.661 & 5.270 & 5.808 & 6.304 & 6.781 \\
\hline 0.010 & 0.928 & 1.798 & 2.624 & 3.332 & 4.039 & 4.671 & 5.238 & 5.818 & 6.317 & 6.809 \\
\hline
\end{tabular}
the optimization method based on AFSA proposed in this paper and the Ioi and Ikeda method is presented in Table 3.

Table 2. Reduction ratio compared to the classical Den Hartog method/\%. 
Table 3. Reduction ratio compared to the Ioi Toshihiro method/\%.

\begin{tabular}{|c|c|c|c|c|c|c|c|c|c|c|}
\hline$\mu$ & 0.010 & 0.020 & 0.030 & 0.040 & 0.050 & 0.060 & 0.070 & 0.080 & 0.090 & 0.100 \\
\hline 0.001 & 3.286 & 1.543 & 1.968 & 1.834 & 1.783 & 1.779 & 1.657 & 1.554 & 1.492 & 1.308 \\
\hline 0.002 & 0.964 & 1.531 & 1.914 & 1.812 & 1.721 & 1.746 & 1.699 & 1.542 & 1.434 & 1.567 \\
\hline 0.003 & 0.989 & 1.293 & 1.232 & 1.391 & 1.619 & 1.712 & 1.715 & 1.778 & 1.693 & 1.580 \\
\hline 0.004 & 0.126 & 0.817 & 1.277 & 1.518 & 1.552 & 1.524 & 1.531 & 1.531 & 1.591 & 1.680 \\
\hline 0.005 & 0.971 & 1.131 & 1.546 & 1.553 & 1.550 & 1.671 & 1.626 & 1.559 & 1.553 & 1.467 \\
\hline 0.006 & 0.651 & 1.286 & 1.275 & 1.365 & 1.568 & 1.549 & 1.575 & 1.638 & 1.573 & 1.529 \\
\hline 0.007 & 0.895 & 0.893 & 0.884 & 1.074 & 1.286 & 1.280 & 1.409 & 1.520 & 1.541 & 1.573 \\
\hline 0.008 & 0.488 & 0.773 & 1.021 & 1.259 & 1.223 & 1.323 & 1.398 & 1.343 & 1.380 & 1.432 \\
\hline 0.009 & 0.615 & 0.878 & 1.090 & 1.260 & 1.252 & 1.379 & 1.388 & 1.368 & 1.394 & 1.326 \\
\hline 0.010 & 0.671 & 0.786 & 1.093 & 1.093 & 1.260 & 1.322 & 1.322 & 1.399 & 1.369 & 1.352 \\
\hline 0.015 & 0.395 & 0.646 & 0.764 & 0.920 & 0.942 & 1.074 & 1.082 & 1.138 & 1.154 & 1.132 \\
\hline 0.020 & 0.144 & 0.351 & 0.520 & 0.655 & 0.795 & 0.811 & 0.897 & 0.893 & 0.930 & 0.981 \\
\hline 0.025 & 0.208 & 0.277 & 0.388 & 0.437 & 0.593 & 0.601 & 0.736 & 0.761 & 0.814 & 0.833 \\
\hline 0.030 & 0.020 & 0.278 & 0.342 & 0.438 & 0.499 & 0.557 & 0.613 & 0.646 & 0.674 & 0.689 \\
\hline 0.035 & 0.101 & 0.121 & 0.196 & 0.224 & 0.327 & 0.364 & 0.458 & 0.499 & 0.562 & 0.587 \\
\hline 0.040 & 0.036 & 0.151 & 0.245 & 0.271 & 0.343 & 0.375 & 0.429 & 0.456 & 0.477 & 0.497 \\
\hline 0.045 & 0.062 & 0.049 & 0.118 & 0.124 & 0.220 & 0.243 & 0.321 & 0.345 & 0.405 & 0.419 \\
\hline 0.050 & 0.075 & 0.073 & 0.169 & 0.187 & 0.246 & 0.262 & 0.313 & 0.316 & 0.320 & 0.309 \\
\hline 0.055 & 0.060 & 0.083 & 0.065 & 0.125 & 0.132 & 0.193 & 0.214 & 0.260 & 0.282 & 0.305 \\
\hline 0.060 & 0.024 & 0.048 & 0.029 & 0.072 & 0.123 & 0.134 & 0.160 & 0.150 & 0.178 & 0.223 \\
\hline 0.065 & 0.061 & 0.061 & 0.083 & 0.085 & 0.123 & 0.130 & 0.170 & 0.182 & 0.191 & 0.188 \\
\hline 0.070 & 0.016 & -0.007 & -0.005 & 0.008 & 0.016 & 0.063 & 0.090 & 0.116 & 0.146 & 0.153 \\
\hline 0.075 & 0.066 & 0.091 & 0.036 & 0.008 & 0.072 & 0.082 & 0.098 & 0.079 & 0.048 & 0.086 \\
\hline 0.080 & 0.041 & 0.030 & 0.037 & 0.034 & 0.062 & 0.066 & 0.094 & 0.097 & 0.102 & 0.091 \\
\hline 0.085 & 0.041 & 0.011 & 0.043 & 0.016 & 0.013 & 0.014 & 0.011 & 0.038 & 0.056 & 0.060 \\
\hline 0.090 & 0.078 & 0.087 & 0.072 & 0.091 & 0.035 & 0.051 & 0.046 & 0.008 & 0.008 & 0.015 \\
\hline 0.095 & 0.058 & 0.077 & 0.025 & 0.066 & 0.039 & 0.044 & 0.052 & 0.045 & 0.033 & 0.041 \\
\hline 0.010 & 0.000 & 0.041 & 0.046 & 0.025 & 0.048 & 0.027 & 0.021 & 0.041 & 0.040 & 0.055 \\
\hline
\end{tabular}

It is presented in Table 2 that the novel optimization method based on AFSA proposed in this paper has a smaller maximum acceleration dynamic amplification factor than the classical Den Hartog method, and in general, the reduction ratio increases with the increasing of the TMD mass ratio and the structural damping ratio. As can be seen in Table 3, the novel optimization method proposed in this paper has a smaller maximum acceleration dynamic amplification factor than the Ioi and Ikeda method, and in general, the reduction ratio increases with the decreasing of the TMD mass ratio and structural damping ratio. Therefore, the novel optimization method based on AFSA proposed in this paper has a better effect in controlling the maximum acceleration dynamic amplification factor.

\section{Case Study}

In this section, an engineering project of a pedestrian bridge, for which TMDs need to be installed, will be introduced in detail as a case study.

The pedestrian bridge is $45 \mathrm{~m}$ long and $6 \mathrm{~m}$ wide. It is a simply supported pedestrian bridge. Due to the excessive vibration under human-induced excitations, it has a serviceability problem. The finite element model was established in Midas Gen. The structural modes are shown in Table 4.

Table 4. Modes of the pedestrian bridge.

\begin{tabular}{cccccccc}
\hline Mode & Frequency/Hz & $\mathbf{U X} / \%$ & $\mathrm{UY} / \%$ & $\mathbf{U Z} / \%$ & $\mathbf{R X} / \%$ & $\mathbf{R Y} / \%$ & $\mathbf{R Z} / \%$ \\
\hline 1 & 1.006 & 94.445 & 3.788 & 0.058 & 0.033 & 0.001 & 0.588 \\
2 & 1.488 & 3.564 & 84.251 & 0.000 & 6.749 & 0.011 & 0.007 \\
3 & 1.946 & 0.063 & 0.026 & 75.499 & 0.208 & 0.014 & 0.000 \\
4 & 2.098 & 0.055 & 2.405 & 0.097 & 41.152 & 0.225 & 0.019 \\
5 & 2.482 & 0.133 & 8.134 & 0.035 & 28.389 & 0.040 & 0.000 \\
6 & 2.726 & 0.594 & 0.006 & 0.001 & 0.029 & 0.000 & 94.733 \\
7 & 4.276 & 0.000 & 0.000 & 0.003 & 0.000 & 0.000 & 0.000 \\
8 & 4.278 & 0.000 & 0.000 & 0.000 & 0.000 & 0.002 & 0.000 \\
9 & 4.425 & 0.026 & 0.002 & 0.000 & 0.002 & 0.390 & 0.003 \\
10 & 4.681 & 0.000 & 0.006 & 0.000 & 0.005 & 43.800 & 0.109 \\
\hline
\end{tabular}

Notes: UX, UY and UZ are modal mass participation coefficient in transverse, longitudinal and vertical direction. $R X, R Y$ and $R Z$ are rotation modal mass participation coefficient in transverse, longitudinal and vertical direction. 
Because the transverse and longitudinal loads of pedestrians are relatively smaller than the vertical load [21], the effect of transverse and longitudinal loads can usually be ignored. From Table 4, it is clear that the third vertical mode is dominant. The third order frequency is $1.946 \mathrm{~Hz}$, and the vertical modal mass participation coefficient is $75.499 \%$. This pedestrian bridge is about $357,500 \mathrm{~kg}$ in total. Therefore, the third vertical modal participation mass is $269,909 \mathrm{~kg}$. The damping ratio of this pedestrian bridge is set to be $2 \%$. The vertical mode shape of the pedestrian bridge is shown in Figure 4 .

In order to solve the serviceability problem, a TMD is designed. The TMD mass ratio was chosen to be $1 \%$. According to Table 1, the TMD frequency ratio is 0.997 and the TMD damping ratio is 0.063 . According to the Den Hartog method, the TMD frequency ratio is 0.995 and the TMD damping ratio is 0.061. According to the Ioi and Ikeda method, the TMD frequency ratio is 0.998 and the TMD damping ratio is 0.064 . The dynamic amplification factors of the three TMDs under different frequency harmonic excitations are compared in Figure 5.

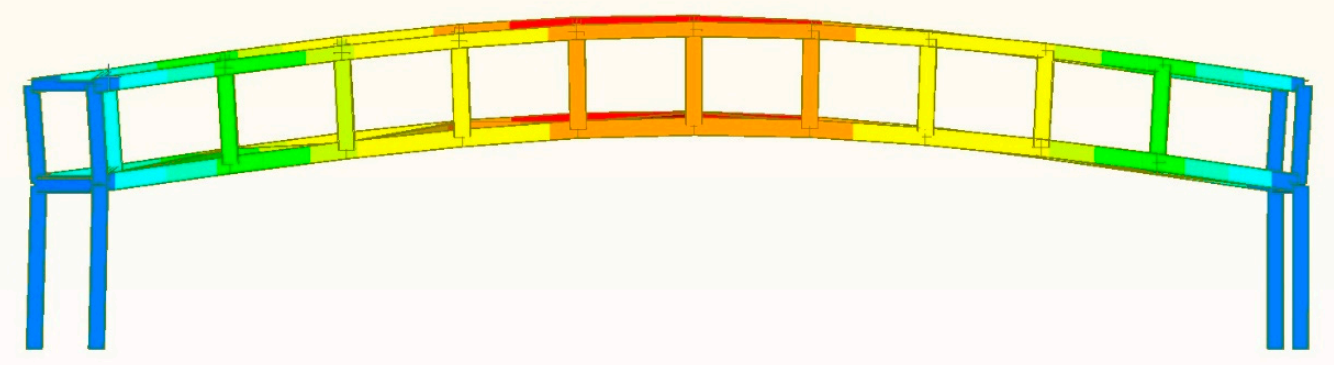

Figure 4. The vertical mode shape of the pedestrian bridge.

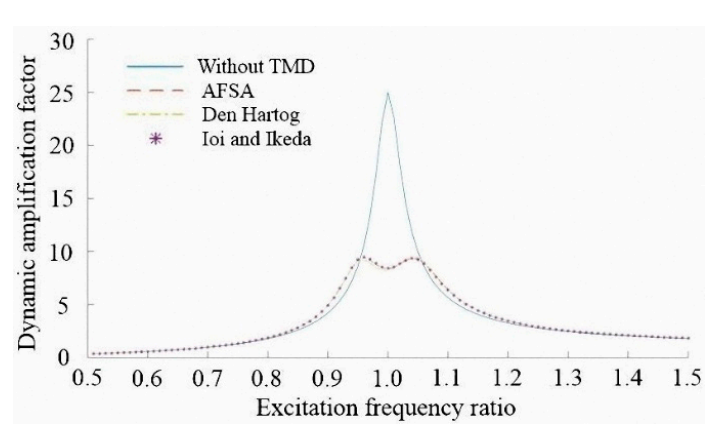

(a)

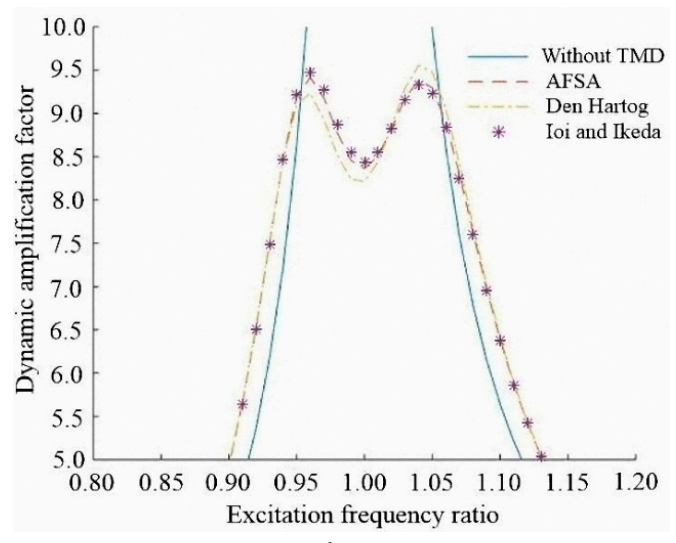

(b)

Figure 5. The comparisons of structural dynamic amplification factors under different frequency harmonic excitations. (a) Excitation frequency ratio from 0.5 to 1.5; (b) Local amplification figure.

It is shown in Figure 5 that the maximum dynamic amplification factor without a TMD is 25.00, while with the TMDs designed based on the AFSA, Den Hartog and Ioi and Ikeda methods it is 9.41, 9.56 and 9.48, respectively. Compared to the situation without a TMD, the TMD designed based on the AFSA, Den Hartog and Ioi and Ikeda methods has a reduction of $62.36 \%, 61.76 \%$ and $62.08 \%$, respectively. It can be seen that the vibration control effect of the TMD designed based on the AFSA method is slightly better than that of the TMD designed based on the remaining two methods.

To further verify the vibration control effect of the optimized TMD designed based on the AFSA, in this section, considering that the frequency of pedestrians is usually around $2.00 \mathrm{~Hz}$, a situation in which a $700 \mathrm{~N}$ person walks, runs and jumps on the middle of the bridge at $2.00 \mathrm{~Hz}$ will be simulated. According to [46-49], a vertical force can be simulated considering of three different frequencies. 
The comparisons of the structural response under $2.00 \mathrm{~Hz}$ walking, running and jumping excitations are shown in Figure 6. Note that the unit of acceleration "gal" means " $1 \mathrm{~cm} / \mathrm{s}^{2}$ ".

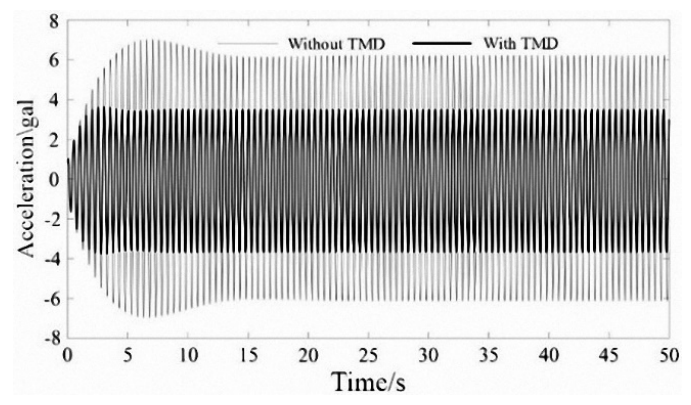

(a)

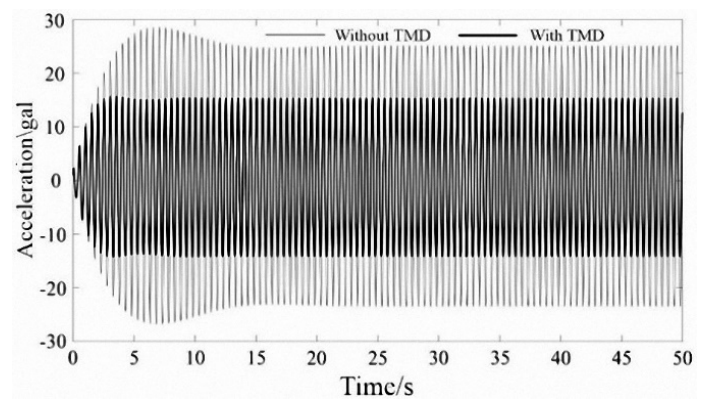

(b)

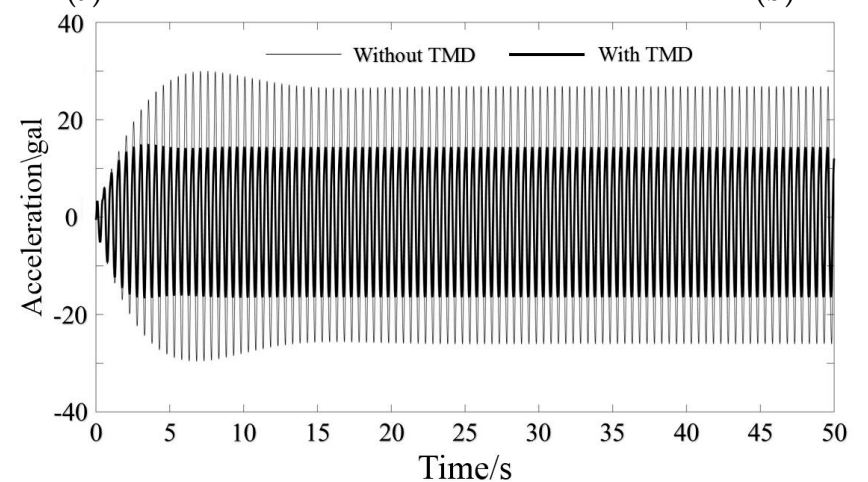

(c)

Figure 6. The comparisons of structural responses under $2.00 \mathrm{~Hz}$ human-induced excitations. (a) Under $2.00 \mathrm{~Hz}$ walking excitation; (b) Under $2.00 \mathrm{~Hz}$ running excitation; (c) Under $2.00 \mathrm{~Hz}$ jumping excitation.

It is presented in Figure 6 that the peak accelerations of structure under walking, running and jumping excitations are $6.24 \mathrm{gal}, 25.17 \mathrm{gal}$ and $26.90 \mathrm{gal}$, respectively, in the situation without TMD, while the peak accelerations are $3.54 \mathrm{gal}, 15.48 \mathrm{gal}$ and $14.39 \mathrm{gal}$, respectively, in the situation with TMD, and the corresponding peak acceleration reductions of TMD are $43.27 \%, 38.50 \%$ and $46.51 \%$, respectively. Consequently, the vibration control effect of an optimized TMD system based on AFSA is quite obvious. Therefore, under the same design guideline, the maximum permissible pedestrian number is larger in the situation with TMD.

\section{Conclusions}

TMD is widely applied in the pedestrian-induced vibration control of pedestrian bridges and its parameters are very important. A new TMD optimization method based on the artificial fish swarm algorithm (AFSA) is proposed in this paper, which takes primary structural damping into consideration. The optimization goal is to minimize the maximum dynamic amplification factor of the primary structure under external harmonic excitation, and the resultant optimized TMD has a smaller maximum dynamic amplification factor and better robustness. The optimum TMD parameters table for a damped primary structure with different damping ratios and different TMD mass ratios was presented. At last, as a case study, the application of an optimized TMD based on AFSA for a pedestrian bridge was proposed. The following conclusions can be drawn:

(1) The fitting formulas of the optimum TMD frequency ratio and the optimum TMD damping ratio agree well with Table 1. Optimum TMD parameters can be obtained from Table 1 or calculated from Formulas (3) and (4). Consequently, the design procedure is very simple.

(2) The novel optimization method proposed in this paper has a smaller maximum acceleration dynamic amplification factor than the classic Den Hartog method and the Ioi and Ikeda method. 
(3) The optimized TMD has a good effect in controlling human-induced vibrations at different frequencies for a pedestrian bridge, indicating its good robustness.

Acknowledgments: This work was supported by the National Natural Science Foundation of China (Grant No. 51478361) and the Fundamental Research Funds for the Central Government Supported Universities.

Author Contributions: Weixing Shi proposed the idea. Liangkun Wang carried out the parametric study and wrote the paper. Zheng Lu conceived the analytical method, provided valuable discussions and revised the paper. Quanwu Zhang carried out case study.

Conflicts of Interest: The authors declare no conflict of interest.

\section{References}

1. Shi, W.; Wang, L.; Lu, Z. Study on self-adjustable tuned mass damper with variable mass. Struct. Control Health Monit. 2017, e2114. [CrossRef]

2. Lu, Z.; Wang, D.; Masri, S.; Lu, X. An experimental study of vibration control of wind-excited high-rise buildings using particle tuned mass dampers. Smart Struct. Syst. 2016, 25, 1-7. [CrossRef]

3. Lu, Z.; Chen, X.; Zhang, D.; Dai, K. Experimental and analytical study on the performance of particle tuned mass dampers under seismic excitation. Earthq. Eng. Struct. Dyn. 2017, 46, 697-714. [CrossRef]

4. Wang, W.X.; Hua, X.G.; Wang, X.Y.; Chen, Z.Q.; Song, G.B. Optimum design of a novel pounding tuned mass damper under harmonic excitation. Smart Mater. Struct. 2017, 26, 055024. [CrossRef]

5. Song, G.B.; Zhang, P.; Li, L.Y.; Singla, M.; Patil, D.; Li, H.N.; Mo, Y.L. Vibration control of a pipeline structure using pounding tuned mass damper. J. Eng. Mech. 2016, 142, 04016031. [CrossRef]

6. Zhang, P.; Song, G.B.; Li, H.N.; Lin, Y.X. Seismic control of power transmission tower using pounding TMD. J. Eng. Mech. 2013, 139, 1395-1406. [CrossRef]

7. Lu, Z.; Lu, X.; Jiang, H.; Masri, S. Discrete element method simulation and experimental validation of particle damper system. Eng. Comput. 2014, 31, 810-823. [CrossRef]

8. Lu, Z.; Chen, X.; Lu, X.; Yang, Z. Shaking table test and numerical simulation of an RC frame-core tube structure for earthquake-induced collapse. Earthq. Eng. Struct. Dyn. 2016, 45, 1537-1556. [CrossRef]

9. Lu, Z.; Wang, Z.; Masri, S.F.; Lu, X. Particle Impact Dampers: Past, Present, and Future. Struct. Control Health Monit. 2018, 25, e2058. [CrossRef]

10. Lu, Z.; Chen, X.; Zhou, Y. An equivalent method for optimization of particle tuned mass damper based on experimental parametric study. J. Sound Vib. 2017, 9. [CrossRef]

11. Lu, Z.; Huang, B.; Zhou, Y. Theoretical study and experimental validation on the energy dissipation mechanism of particle dampers. Struct. Control Health Monit. 2017, 11. [CrossRef]

12. Dai, K.; Wang, J.; Mao, R.; Lu, Z.; Chen, S. Experimental investigation on dynamic characterization and seismic control performance of a TLPD system. Struct. Des. Tall Spec. Build. 2017, 26, e1350. [CrossRef]

13. Lu, Z.; Lu, X.; Masri, S.F. Studies of the performance of particle dampers under dynamic loads. J. Sound Vib. 2010, 329, 5415-5433. [CrossRef]

14. Casciati, F.; Casciati, S.; Faravelli, L. A contribution to the modelling of human induced excitation on pedestrian bridges. Struct. Saf. 2017, 66, 51-61. [CrossRef]

15. Brownjohn, J.M.W.; Paivc, A. Experimental methods for estimating modal mass in footbridges using human-induced dynamic excitation. Eng. Struct. 2007, 29, 2833-2843. [CrossRef]

16. Nakhorn, P.; Sopak, K.; Pennung, W. Application of non-linear multiple tuned mass dampers to suppress man-induced vibrations of a pedestrian bridge. Earthq. Eng. Struct. Dyn. 2010, 32, 1117-1131.

17. Chen, S.R.; Wu, J. Performance enhancement of bridge infrastructure systems: Long-span bridge, moving trucks and wind with tuned mass dampers. Eng. Struct. 2008, 30, 3316-3324. [CrossRef]

18. Carpineto, N.; Lacarbonara, W.; Vestroni, F. Mitigation of pedestrian-induced vibrations in suspension footbridges via multiple tuned mass dampers. J. Vib. Control 2010, 16, 749-776. [CrossRef]

19. Lu, X.; Ding, K.; Shi, W.; Weng, D. Tuned mass dampers for human-induced vibration control of the Expo Culture Centre at the World Expo 2010 in Shanghai, China. Struct. Eng. Mech. 2012, 43, 607-621. [CrossRef]

20. Li, Q.; Fan, J.; Nie, J.; Li, Q.; Chen, Y. Crowd-induced random vibration of footbridge and vibration control using multiple tuned mass dampers. J. Sound Vib. 2010, 329, 4068-4092. [CrossRef] 
21. Lievens, K.; Lombaert, G.; Roeck, G.; Broeck, P. Robust design of a TMD for the vibration serviceability of a footbridge. Eng. Struct. 2016, 123, 408-418. [CrossRef]

22. Caetano, E.; Cunha, Á.; Moutinho, C.; Magalhães, F. Studies for controlling human-induced vibration of the Pedro e Inês footbridge, Portugal. Part 2: Implementation of tuned mass dampers. Eng. Struct. 2010, 32, 1082-1091. [CrossRef]

23. Casciati, F.; Giuliano, F. Performance of multi-TMD in the towers of suspension bridges. J. Vib. Control 2009, 15, 821-847. [CrossRef]

24. Nagarajaiah, S. Adaptive passive, semi-active, smart tuned mass dampers: Identification and control using empirical mode decomposition, Hilbert transform, and short-term Fourier transform. Struct. Control Health Monit. 2009, 16, 800-841. [CrossRef]

25. Sun, C.; Nagarajaiah, S.; Dick, A.J. Family of smart tuned mass damper with variable frequency under harmonic excitation and ground motions: Closed-form evaluation. Smart Struct. Syst. 2014, 13, 319-341. [CrossRef]

26. Sun, C.; Nagarajaiah, S. Study on semi-active tuned mass damper with variable damping and stiffness under seismic excitations. Struct. Control Health Monit. 2013, 21, 890-906. [CrossRef]

27. Lu, Z.; Yang, Y.; Lu, X.; Liu, C. Preliminary study on the damping effect of a lateral damping buffer under a debris flow load. Appl. Sci. 2017, 7, 201. [CrossRef]

28. Lu, X.; Liu, Z.; Lu, Z. Optimization design and experimental verification of track nonlinear energy sink for vibration control under seismic excitation. Struct. Control Health Monit. 2017, 24, e2033. [CrossRef]

29. Den Hartog, J.P. Mechanical Vibration, 4th ed.; McGraw-Hill: New York, NY, USA, 1956.

30. Leung, A.Y.T.; Zhang, H. Particle swarm optimization of tuned mass dampers. Eng. Struct. 2009, 31, 715-728. [CrossRef]

31. Leung, A.Y.T.; Zhang, H.; Cheng, C.C.; Lee, Y.Y. Particle swarm optimization of TMD by non-stationary base excitation during earthquake. Earthq. Eng. Struct. Dyn. 2008, 37, 1223-1246. [CrossRef]

32. Bekdas, G.; Nigdeli, S.M. Estimating optimum parameters of tuned mass dampers using harmony search. Eng. Struct. 2011, 33, 2716-2723. [CrossRef]

33. Mohebbi, M.; Shakeri, K.; Ghanbarpour, Y.; Majzoub, H. Designing optimal multiple tuned mass dampers using genetic algorithms (GAs) for mitigating the seismic response of structures. J. Vib. Control 2012, 19, 605-625. [CrossRef]

34. Jiménez-Alonso, J.F.; Sáez, A. Robust optimum design of TMDs to mitigate pedestrian induced vibrations using multi-objective genetic algorithms. Struct. Eng. Int. 2017, 4, 492-501. [CrossRef]

35. Li, X.; Shao, Z.; Qian, J. An optimizing method based on autonomous animates: Fish swarm algorithm. Chin. J. Syst. Eng. Theory Pract. 2002, 22, 32-38.

36. Wang, L.; An, L.; Pi, J.; Fei, M.; Pardalos, P. A diverse human learning optimization algorithm. J. Glob. Optim. 2017, 67, 283-323. [CrossRef]

37. Toi, T.; Ikeda, K. On the dynamic vibration damped absorber of the vibration system. JSME Int. J. 1978, 21, 64-71.

38. Ikeda, K.; Toi, T. On the houde damper for a damped vibration system. Trans. Jpn. Soc. Mech. Eng. Ser. C 1979, 45, 663-670. [CrossRef]

39. Butz, C.; Feldmann, M.; Heinemeyer, C. Advanced load models for synchronous pedestrian excitation and optimised design guidelines for steel footbridges. Agrociencia 2013, 47, 781-794.

40. Van Nimmen, K.; Verbeke, P.; Lombaert, G.; De Roeck, G. Numerical and experimental evaluation of the dynamic performance of a footbridge with tuned mass dampers. J. Bridg. Eng. ASCE 2016, 21, C4016001. [CrossRef]

41. Asami, T.; Nishihara, O.; Baz, A.M. Analytical solutions to $\mathrm{H}_{\infty}$ and $\mathrm{H}_{2}$ optimization of dynamic vibration absorbers attached to damped linear systems. J. Vib. Acoust. 2002, 124, 284-295. [CrossRef]

42. Wang, H.; Fan, C.; Tu, X. AFSAOCP: A novel artificial fish swarm optimization algorithm aided by ocean current power. Appl. Intell. 2016, 45, 992-1007. [CrossRef]

43. Liu, Q.; Odaka, T.; Kuroiwa, J.; Shirai, H.; Ogura, H. An artificial fish swarm algorithm for the multicast routing problem. Ieice Trans. Commun. 2014, 97, 996-1011. [CrossRef]

44. Neshat, M.; Sepidnam, G.; Sargolzaei, M.; Toosi, A. Artificial fish swarm algorithm: A survey of the state-of-the-art, hybridization, combinatorial and indicative applications. Artif. Intell. Rev. 2014, 42, 965-997. [CrossRef] 
45. Zhu, X.; Ni, Z.; Cheng, M.; Jin, F.; Li, J.; Weckman, G. Selective ensemble based on extreme learning machine and improved discrete artificial fish swarm algorithm for haze forecast. Appl. Intell. 2017, 3, 1-19. [CrossRef]

46. Casado, C.; Díaz, I.; Sebastián, J.; Poncela, A.; Lorenzana, A. Implementation of passive and active vibration control on an in-service footbridge. Struct. Control Health Monit. 2013, 20, 70-87. [CrossRef]

47. Nimmen, K.; Lombaert, G.; Roeck, G.; Broeck, P. Vibration serviceability of footbridges: Evaluation of the current codes of practice. Eng. Struct. 2014, 59, 448-461. [CrossRef]

48. Occhiuzzi, A.; Spizzuoco, M.; Ricciardelli, F. Loading models and response control of footbridges excited by running pedestrians. Struct. Control Health Monit. 2008, 15, 349-368. [CrossRef]

49. Shi, W.; Wang, L.; Lu, Z.; Gao, H. Study on adaptive-passive and semi-active eddy current tuned mass damper with variable damping. Sustainability 2018, 10, 99. [CrossRef]

(C) 2018 by the authors. Licensee MDPI, Basel, Switzerland. This article is an open access article distributed under the terms and conditions of the Creative Commons Attribution (CC BY) license (http:/ / creativecommons.org/licenses/by/4.0/). 